\title{
Avaliando um Ambiente Virtual de Aprendizagem para as aulas de Ciências no nono ano a partir de percepções dos alunos
}

Roberta Dall Agnese da Costa

Caroline Medeiros Martins de Almeida

Paulo Tadeu Campos Lopes

\section{Resumo}

Este trabalho buscou avaliar um Ambiente Virtual de Aprendizagem (AVA) a partir das percepções dos alunos, como componente on-line e complementar da disciplina de Ciências no nono ano de uma escola pública. A metodologia enquadra-se no paradigma qualitativo, conduzida pela abordagem do estudo de caso e utilizando-se de questionários para a coleta de dados. As questões fechadas foram analisadas através da estatística descritiva e as questões abertas segundo a técnica da análise de conteúdo. Nos resultados é apresentado o perfil da turma e uma avaliação detalhada das percepções dos alunos. De um modo geral, pode-se concluir que o AVA contribuiu para a aprendizagem e cumpriu as expectativas pedagógicas que fundamentaram sua elaboração, dentre elas: oportunizar materiais de melhor qualidade visual aos alunos; estimular a aprendizagem em diferentes contextos; respeitar e valorizar o ritmo de aprendizagem de cada aluno e aumentar o tempo de dedicação dos alunos ao estudo de Ciências.

Palavras-chave: Tecnologias da informação e da comunicação; Ambiente virtual de aprendizagem; ensino e aprendizagem em Ciências.

\section{Abstract \\ Evaluating a virtual learning environment for the classes of sciences in the ninth year from the perceptions of students}

This study investigated the perceptions of students about the use of a Virtual Learning Environment (VLE), as online component and complementary Science discipline in the ninth year in a public school in the city of Canoas / RS. The methodology is based on the qualitative paradigm, conducted by the case study approach and using questionnaires for data generation. To collect the data we chose to questionnaires. Closed questions by analyzed by descriptive statistics tools and open questions using the technique of content analysis. The results shows the profile of the class and a detailed assessment of the perceptions of students, held at the end of the proposal. In general, it can be concluded that the AVA contributed to student learning and fulfill its educational expectations that underlie their development, among them: let Material best visual quality students; stimulate learning in different contexts; respect and value the pace of learning of each student and increase the time dedicated to the study of students of Sciences.

Keywords: Information and communication technologies; Virtual learning environment; teaching and learning of Science. 


\section{Introdução}

Vivemos na era da informação, em que a velocidade de produção e compartilhamento do conhecimento é incrivelmente alta. Em virtude desta rapidez, as formas de ensinar e aprender têm se modificado, tornando-se cada vez mais desafiadoras e complexas. A escola, enquanto instituição formadora da população deve acompanhar estas mudanças e procurar adequar suas práticas a essas novas formas de ensinar e aprender.

$\mathrm{Na}$ era da informação, a internet ganha um destaque especial, pois é ela quem subsidia grande parte dos meios para compartilhar o conhecimento. A internet possibilita ferramentas que podem ser importantes contributos para os processos de ensino e da aprendizagem.

Dentre as diversas ferramentas, os Ambientes Virtuais de Aprendizagem (AVA) passam a ocupar um lugar de destaque como facilitadores e articuladores de aprendizagens diferenciadas. Estes AVA são novos ambientes de convivência que levam a diferentes modos de interação entre os sujeitos e a sociedade do conhecimento (PAULETTI e CATELLI, 2013).

De modo simplificado um AVA é a terminologia mais conhecida para fazer menção a um ambiente desenvolvido na internet através de diferentes recursos tecnológicos a fim de criar um contexto educacional que possibilita diferentes tipos de interação entre aluno, professor e conteúdo (TAVARES, 2003).

Neste sentido, a relação entre o uso das Tecnologias da Informação e da Comunicação (TIC) e o desenvolvimento de metodologias de ensino e aprendizagem centradas nas necessidades dos professores e dos alunos fica cada vez mais evidente. Por suas especificidades, essas metodologias podem ser capazes de criar melhores expectativas, tanto nos professores quanto nos alunos, no que diz respeito ao seu desempenho e com isso aperfeiçoar os processos de ensino e aprendizagem.

Reconhecendo a importância do ensino de Ciências e os desafios que os professores têm enfrentado para utilizar as TIC na educação básica pública é que se coloca o problema de pesquisa deste trabalho: Quais as percepções dos alunos sobre a utilização de um AVA como componente on-line e complementar nas aulas de Ciências no nono ano?

Para tanto, partiu-se do pressuposto de que o uso de um AVA pode contribuir de diferentes formas para o ensino e a aprendizagem em Ciências. Além disso, na escolha do método e dos instrumentos de coleta de dados que dão importância às percepções dos sujeitos, demonstra-se o viés crítico-reflexivo desta pesquisa.

\section{Caracterização da pesquisa}

O público-alvo da pesquisa consistiu em trinta e seis alunos de uma turma do nono de uma escola pública no município de Canoas, RS, no primeiro semestre de 2014. A metodologia escolhida para pesquisa enquadra-se no paradigma qualitativo, conduzida pela abordagem do 
estudo de caso e utilizando-se de instrumentos etnográficos (questionários) para a geração de dados (GODOY, 1995; YIN, 2001).

Quanto aos procedimentos de análise dos dados gerados através dos questionários, utilizaram-se ferramentas de estatística descritiva para as questões abertas e as questões fechadas foram analisadas por meio de um conjunto de técnicas da análise de conteúdo, conforme o modelo proposto por Bardin (2011).

Foi necessário elaborar um AVA que se tornou um componente complementar à disciplina, caracterizando esta metodologia de ensino como bimodal. No ensino bimodal as aulas ocorrem normalmente na escola e, paralelamente a elas existe um AVA em que são inseridos conteúdos, atividades, leituras complementares, vídeos e outros objetos de aprendizagem. Desta forma, utilizou-se uma situação real de sala de aula comum à disciplina de Ciências nas escolas públicas brasileiras.

Para desenvolver um AVA que atendesse as necessidades específicas deste grupo de alunos foi adaptada uma plataforma de criação e edição de sites on-line, a Wix.com. A Wix.com foi escolhida por possibilitar a criação um AVA aberto, ou seja, sem a necessidade de logar os alunos, além disso, disponibiliza uma área de programação fácil e intuitiva, que se assemelha muito aos editores de texto ou de apresentações comumente utilizados.

A Wix.com é uma plataforma on-line de criação e edição de sites fundada em 2006, que permite aos usuários criar em $\mathrm{HTML}^{5}$, sites mobile (adaptados para o uso específico em celulares) e páginas customizadas para o Facebook. Para criar o site, a plataforma disponibiliza centenas de modelos prontos (templates), ferramentas do tipo arrastar-e-soltar, hospedagem profissional e também uma loja de aplicativos (App Market) que permite inserir formulários de contato, pesquisas, chats e muito mais, tudo gratuitamente.

Como se percebe, a Wix.com não foi criada com o objetivo de ser utilizado na Educação, nem de ser uma construtora de AVA, porém por suas características específicas e em função das grandes possibilidades de adaptação que ela apresenta, pode ser uma ferramenta utilizável no contexto escolar.

Sobre o tema, Valentini e Soares (2010) lembram que um AVA é uma interface social, que se constitui de interações cognitivo-sociais sobre ou em torno de um objeto de conhecimento. Sabe-se também que o fundamental não é a interface em si, mas o que os interagentes fazem com ela. Nesse sentido, utilizar a Wix.com no ambiente escolar é uma possibilidade, uma vez que o principal determinante de um AVA não é sua interface, mas sim o plano pedagógico que sustenta a configuração deste ambiente (VALENTINI e SOARES, 2010). Detalhes da elaboração, os objetivos e o conteúdo do AVA estão descritos a seguir, organizados em abas.

A ideia da primeira aba, a Página Inicial (Figura 1), era recepcionar os alunos, algo semelhante a uma capa. Nesta aba foram acrescentadas frases motivacionais como, por exemplo, 
"Este site foi criado para vocês" e "Sala de aula on-line - Para aproveitar o máximo do conhecimento". Nesta página foi acrescentado um botão "Curtir" e "Comentar" do Facebook. Este recurso está disponível na própria plataforma Wix.com e pode ser facilmente incorporado a qualquer site criado, tornando-o integrado as principais redes sociais.

A rede social Facebook tem uma grande audiência entre a população brasileira em geral e, com os alunos isso não é diferente. O Facebook pode ser incorporado ao ensino e a aprendizagem de diferentes modos, pois permite a colaboração no processo educativo e ainda a construção crítica e reflexiva do conhecimento (FERNANDES, 2011; JULIANI, 2012).

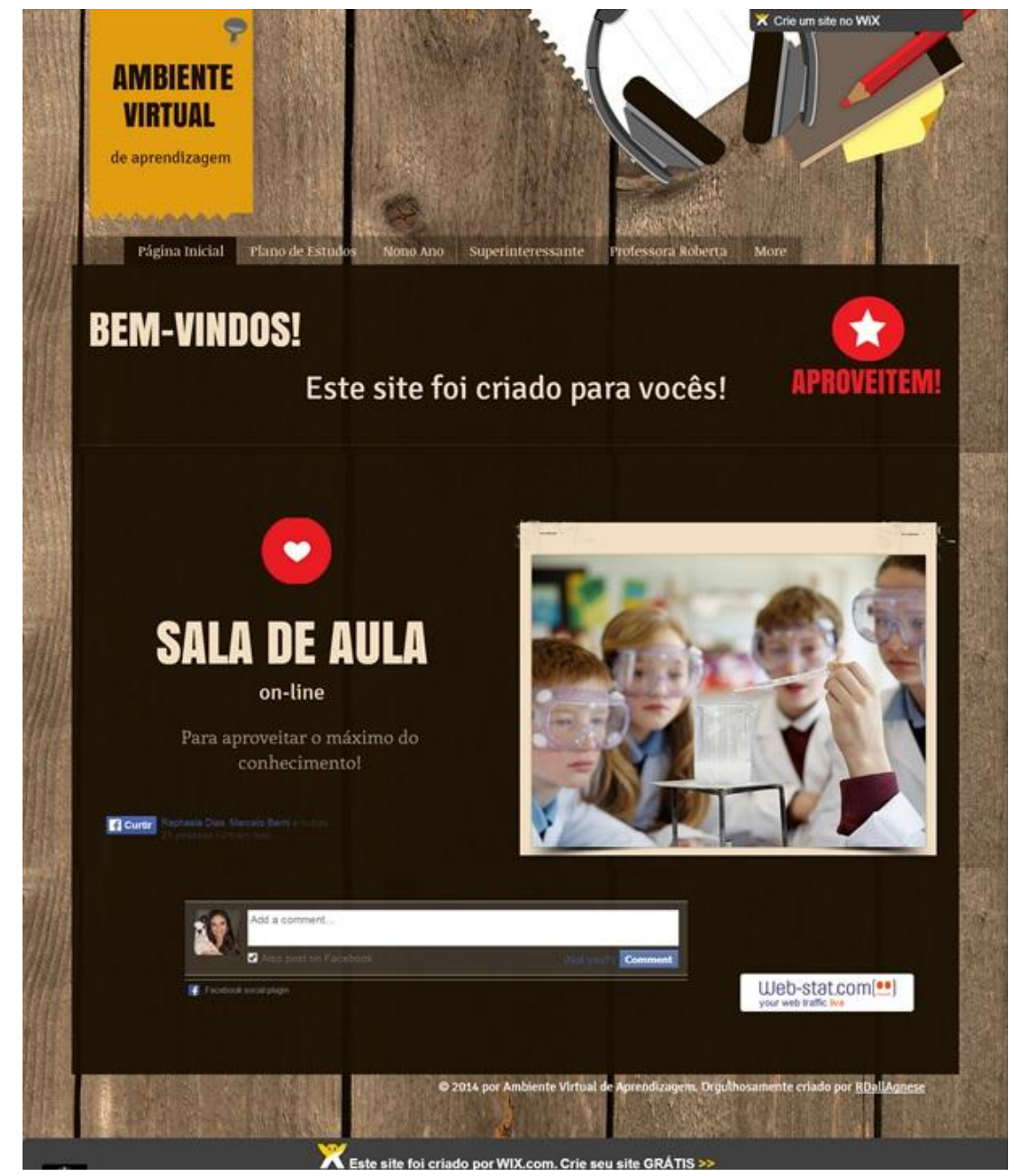

Figura 1 - Capa do AVA Ciências - Nós Amamos Ciências.

(Fonte: AVA Ciências - Nós amamos Ciências. Disponível em: http://avaciencias.wix.com/nosamamosciencias)

Na segunda aba criada, Plano de Estudos, os alunos podiam acessar o programa da disciplina que incluía informações como: carga horária semanal e anual da disciplina, objetivos gerais, conteúdos e objetivos específicos, metodologia, descrição do processo de avaliação e a 
bibliografia fundamental e complementar. Além de acessar estas informações no site, foi acrescentado nesta página um botão de download (disponível na plataforma Wix.com) através do qual os alunos poderiam baixar o arquivo e salvá-lo em seu computador para ter acesso off-line.

Este material foi disponibilizado com o objetivo principal de auxiliar os alunos na organização pessoal em relação às etapas de desenvolvimento do conteúdo. Acredita-se que, desta forma, o aluno é incentivado a reconhecer o processo de aprendizagem como um todo, compreendendo onde começa e até onde iremos com o conteúdo, podendo assim estabelecer relações entre os conhecimentos.

A terceira aba, Nono ano (Figura 2), por sua vez, concentrava a parte principal do AVA, onde os alunos podiam acessar vídeos do Youtube, os conteúdos em Prezi e realizar as atividades através do EducaPlay. Os conteúdos foram organizados em unidades de estudos.

O Youtube (disponível em https://www.youtube.com) é um site que permite que os usuários assistam, carreguem e compartilhem vídeos em formato digital. Sobre o uso de vídeos em sala de aula, Moran (2009) lembra que a linguagem do vídeo está mais próxima da linguagem dos jovens, pois se distância do gênero do livro didático, da linearidade das atividades escolares e da rotina escolar.

O Prezi (disponível em http://prezi.com/_) é um software que disponibiliza uma versão gratuita para a criação de apresentações não lineares, animadas de maneira dinâmica e que não se limitam aos tradicionais slides. Sobre esse assunto, Martinho e Pombo (2009) ressaltam que o uso da técnica de projeções de imagens durante o ensino, pode influenciar de forma positiva a aprendizagem, pois aumenta a atenção dos alunos e seu entusiasmo para aprender.

O EducaPlay (disponível em: http://www.educaplay.com/ ) é uma plataforma para a criação de atividades educacionais multimídia. Em relação às vantagens deste tipo de recurso pode-se citar o fato de permitir ao professor organizar ferramentas personalizadas de avaliação utilizando-se das TIC de forma bastante simples e rápida (MORAN, 2009).

Ao ter acesso a vídeos complementares, aos conteúdos em Prezi e as atividades através do EducaPlay os alunos podiam interagir de diferentes formas com o conhecimento através do uso das TIC. Confirmando assim, que as TIC podem se tornar elementos importantes no ensino e na aprendizagem, pois além de criar diferentes possibilidades de aprendizagem também melhoram as expectativas dos professores e dos alunos em relação aos processos (MARTINHO e POMBO, 2009). 


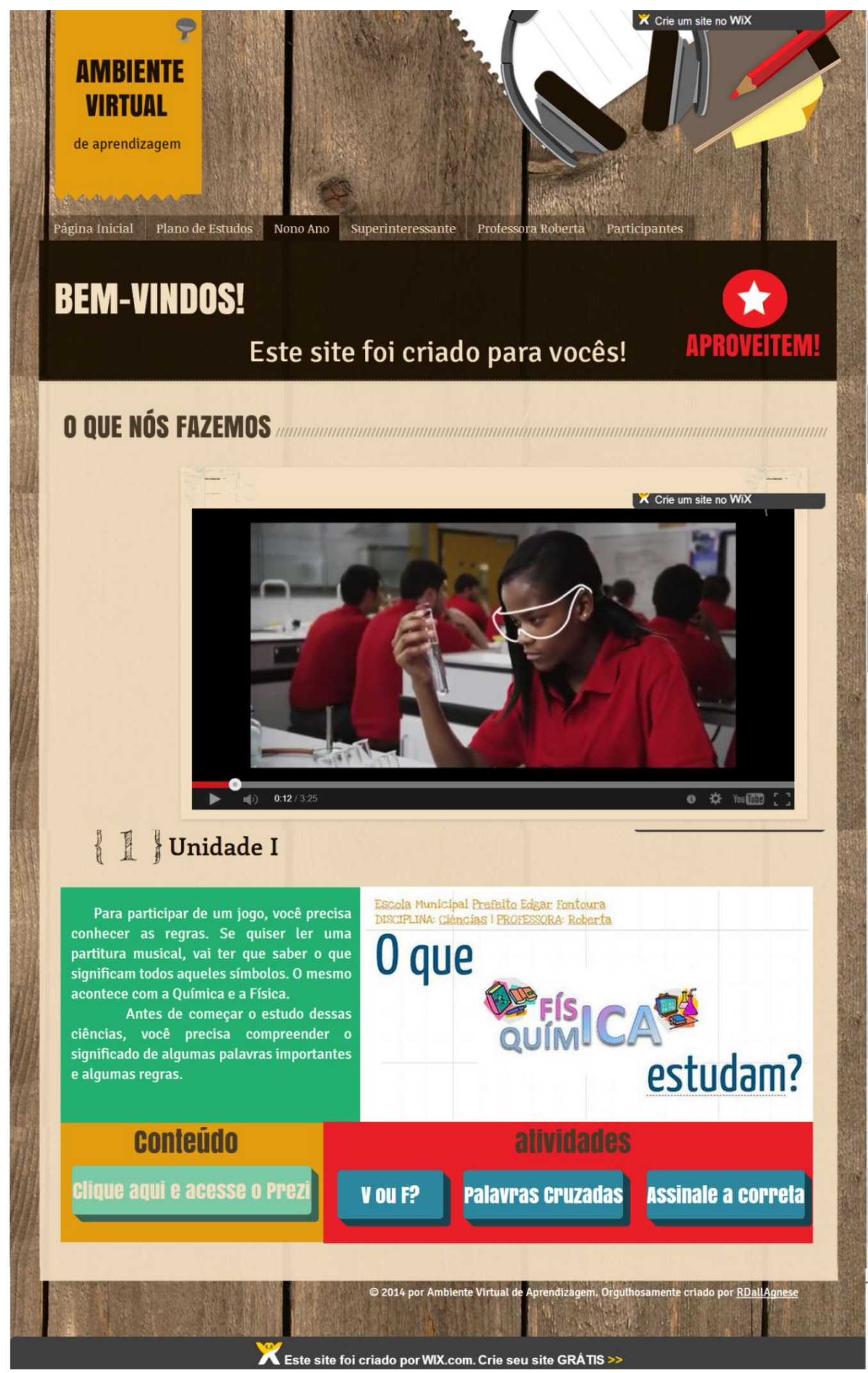

Figura 2 - Aba Nono ano.

(Fonte: AVA Ciências - Nós Amamos Ciências. Disponível em: http://avaciencias.wix.com/nosamamosciencias\#!nonoano/cee5) 
A quarta aba, Superinteressante, apresentava chamadas para leituras curiosas e interessantes sobre diversos assuntos. As leituras eram disponibilizadas através do site da revista Superinteressante (disponível em: http://super.abril.com.br/ ). Esta aba foi criada com o objetivo de estimular a leitura através de assuntos curiosos e complementares aos conteúdos de Ciências vistos no decorrer da vida estudantil.

Percebe-se, atualmente, que os alunos leem cada vez menos. O hábito da leitura deixou de ser um prazer para esta geração de nativos digitais (PALFREY e GASSER, 2011). A leitura tornou-se um desafio para os professores, pois não há aprendizado que se configure sem leitura e interpretação.

Para responder a este desafio, propõe-se a utilização de textos em formato digital, que podem se apresentar das mais diferentes formas para os leitores. Esta apresentação tem configurado uma nova plasticidade de texto e imagem, que só é possível em dispositivos interativos (LÉVY,2001).

Vetromille-Castro (2003) também compartilha a ideia de formação de um aluno-leitor mais ativo em relação às novas formas de apresentação do texto, indicando que a leitura virtual é diferente da leitura em sala de aula. Isso acontece, pois, quando o aluno usa a internet para a leitura pode construir seu próprio hipertexto, através dos múltiplos caminhos de leitura que se apresentam. Cabe destacar que, mesmo a leitura de um texto impresso pode proporcionar múltiplos caminhos, dependendo apenas das escolhas e das preferências do leitor.

A quinta aba foi criada para abrigar alguns dos instrumentos de geração de dados como, por exemplo, os questionários.

Com o objetivo de proporcionar acesso democrático ao AVA, todos os alunos foram convidados a participar da proposta. Por se tratarem de menores de idade foi realizada uma reunião explicativa com os pais. Nesta reunião os pais presentes assinaram um Termo de Consentimento, autorizando os filhos a participarem da proposta e também a utilização dos dados coletados. Para os pais que não puderam comparecer à reunião foi enviada uma carta contento o mesmo Termo de Consentimento. Os alunos retornaram o termo assinado para a professora-pesquisadora.

Em relação à coleta de dados, diversos autores concordam que a internet pode ser uma ferramenta facilitadora para a coleta. Além disso, através da internet é possível utilizar instrumentos de coleta de dados conhecidos e agregar a eles as facilidades da rapidez e da assincronia (MENEZES, 2009). Nesta pesquisa, um dos instrumentos de coleta de dados, o Questionário I foi aplicado utilizando a internet.

O Questionário I tinha o objetivo de levantar informações sobre o perfil da turma tanto em relação às características pessoais quanto a forma e experiência com o uso da internet. Contendo dez questões fechadas, ele foi elaborado com base em um aplicativo disponibilizado na 
plataforma Wix, o 123 Form Builder. O aplicativo permite configurar uma conta de e-mail para receber as respostas, além ser possível acessá-las pelas configurações do próprio aplicativo.

A escolha por este formato de questionário foi orientada, principalmente, pela vantagem de aparecer igual para todos os respondentes, além de ter uma aparência atrativa, utilizando-se da formatação de textos, cores e gráficos. Também por ser de fácil preenchimento por parte dos respondentes que apenas precisam selecionar uma opção entre respostas pré-definidas (MAN e STEWART, 2002).

O segundo instrumento de coleta de dados também foi um questionário (Questionário II), porém aplicado de forma presencial, na sala de aula, durante as aulas de Ciências. Este questionário tinha o objetivo de avaliar os efeitos causados pela intervenção através da reflexão crítica dos alunos participantes. Composto por vinte questões, sendo oito fechadas e doze abertas.

\section{Resultados e discussão}

O primeiro instrumento de coleta de dados foi o Questionário I. Os resultados estão expressos a seguir.

$\mathrm{Na}$ primeira questão os alunos responderam sobre a participação em AVA: $52 \%$ responderam que nunca havia participado e $48 \%$ já havia. Esse alto índice de alunos que já participaram de um AVA pode ser explicado por um projeto piloto desenvolvido no ano anterior (oitavo ano).

A segunda questão, relacionada ao acesso a internet, $61 \%$ responderam que tem acesso à internet banda larga em casa. Da mesma forma na terceira questão, a maioria (também 61\%) indicou que costuma utilizar acesso wi-fi quando disponibilizado por lojas, restaurantes ou outros estabelecimentos.

Com o objetivo de ter maior precisão em relação às informações sobre o uso da internet, os alunos foram questionados sobre o número de horas que permanecem conectados (quarta questão). A maioria deles, 59\% indicou que permanece o dia todo conectado, enquanto que $19 \%$ deles permanece mais de três horas, $11 \%$ mais de uma hora e outros $11 \%$ menos de uma hora. É possível concluir que estes alunos pertencem à chamada geração de nativos digitais. É uma geração que tem a sua disponibilidade uma facilidade muito grande de recursos para acessar a internet, deste modo, é comum permanecem o dia inteiro conectados via smartphones e tablets (PIVA JR, 2013). Este fato foi importante para a continuação da pesquisa, uma vez que os alunos tem facilidade de acesso à internet fora da escola, a proposta pode se efetivar (pois na escola não estava disponível). 
Na quinta questão, em se tratando dos conhecimentos em informática $50 \%$ classificou-os como básicos e $50 \%$ como intermediários. Nenhum aluno considerou seus conhecimentos em informática avançados. O que se percebe, de um modo geral, é que os alunos conhecem e utilizam muito as redes sociais e outros aplicativos, porém desconhecem a funcionalidade de programas de produtividades como editores de textos, de planilhas ou apresentações. Neste sentido, Onofre (2010) ressalta que o aluno da atualidade necessita aprimorar sua relação com as ferramentas computacionais para fazer parte de uma sociedade conhecida como sociedade da informação.

A maioria dos alunos (86\%) respondeu na sexta questão que utiliza a internet como ferramenta para auxiliar nos estudos. Esses alunos tiveram que especificar o que fazem na internet para auxiliar nos estudos (sétima questão): a maioria, 39\% dos alunos indicou que utiliza a internet para procurar textos sobre os assuntos da aula. Esta informação foi importante para a elaboração do AVA, pois evidenciou a procura dos alunos por materiais de referência para os estudos na internet. Assim surgiu a ideia de disponibilizar os conteúdos no formato de apresentações em Prezi no AVA, para que eles pudessem ter um material de qualidade para estudar em casa.

Cabe ressaltar que, os alunos utilizam a internet não só pelos computadores, mas também pelos tablets e celulares (71\%), como apontado pela oitava questão. Este fato foi importante na escolha da plataforma para criar o AVA, pois ela precisava ser facilmente adaptável para estas outras formas de acesso, como a mobile por exemplo.

Com o objetivo de planejar atividades que pudessem ser o mais adaptadas à turma, os alunos foram questionados sobre a estratégia de aprendizado que consideram mais contribuir para seus estudos (nona questão). Em relação às preferências dos alunos às diferentes estratégias de aprendizado, $36 \%$ deles optaram pela utilização de imagens, esquemas e gráficos, ressaltando o caráter visual deste tipo de aprendizagem. Outros $25 \%$ apontaram o uso de dinâmicas de memorização e repetição, e outros $25 \%$ indicaram a utilização de músicas e filmes. Para completar, apenas $14 \%$ revelou fazer uso de técnicas de leitura e escrita, ressaltando a pouca familiaridade com o hábito da leitura.

Este tipo de questionamento ajudou a identificar estratégias que realmente teriam impacto positivo sobre a aprendizagem deste grupo de alunos, uma vez que, a partir delas as unidades de estudo foram organizadas.

Devido à popularização das redes sociais e da facilidade criar páginas pessoais (como blogs, por exemplo), os alunos foram questionados (décima questão) sobre a participação como autor, colaborar ou comentarista em blogs ou funpages (páginas do Facebook). Dentre os alunos, $81 \%$ responderam que não participam de blogs ou funpages, desvelando um novo nicho de pesquisa.

192 DOI: Em andamento.

R. Bras. de Ensino de C\&T 
O Questionário II contribuiu para a avaliação final da proposta. Nele havia uma distinção entre os alunos que haviam acessado ao AVA e os que não, logo na primeira questão. Assim sendo, quem não havia acessado ao AVA responderia apenas a uma questão, explicitando os motivos do não acesso, enquanto que os alunos que haviam acessado ao AVA responderiam a vinte questões. Dentre as vinte questões, oito eram fechadas em que os alunos deveriam optar por uma das respostas previamente determinadas e doze questões eram abertas.

Cabe ressaltar que, a este questionário responderam 35 alunos, e não os 36 alunos que compunham a turma. Um aluno estava afastado das atividades escolares por determinação médica.

Na primeira questão que tratava sobre o acesso ao AVA, 69\% dos alunos responderam que acessaram o AVA, enquanto que $31 \%$ responderam que não haviam acessado. Considerando que o acesso foi totalmente fora da escola, pode-se dizer que o AVA teve uma boa aceitação por parte dos alunos, despertando o interesse e a curiosidade para o acesso. Os alunos que não haviam acessado o AVA, $64 \%$ indicaram o fato de estar sem internet disponível em casa e $27 \%$ informaram que estão sem computador

Os alunos que não haviam acessado deveriam expor o porquê do não acesso, desta forma, $73 \%$ dos alunos indicaram estar sem computador em casa, $45 \%$ responderam que estavam sem acesso à internet e apenas $9 \%$ indicaram que não acessam muito a internet.

Os alunos que haviam acessado ao AVA continuavam a responder. A primeira questão era referente à frequência de acesso ao AVA. Optou-se por uma questão aberta para dar mais fidedignidade e precisão aos dados. Desta forma, as respostas foram as mais variadas, sendo que $38 \%$ indicaram acessar algumas vezes (sem detalhar) e outros $38 \%$ antes das avaliações.

Na segunda questão, referente ao tempo de acesso ao AVA, $42 \%$ dos alunos informaram que permaneceram em média uma hora acessando o AVA, enquanto que a segunda posição, com $34 \%$, indicaram que permanecem trinta minutos conectados por acesso.

$\mathrm{Na}$ terceira questão, deveriam responder se acessam o material disponível antes da aula correspondente: $59 \%$ dos alunos responderam positivamente e $41 \%$ responderam que não acessam. Na quarta questão os alunos deveriam avaliar o grau de dificuldades das atividades propostas no AVA, dentre os graus de dificuldade previstos, $88 \%$ classificaram-nas como de nível médio, $8 \%$ fáceis e apenas $4 \%$ como difíceis.

Na quinta questão os alunos deveriam avaliar se a utilização do AVA aumentou seu tempo de estudos em Ciências, assim sendo, $88 \%$ dos alunos responderam que sim e $12 \%$ que não. Este fato se demonstra relevante e significativo, pois indica que o AVA está cumprindo com um dos seus objetivos pedagógicos que é aumentar a dedicação dos alunos aos estudos. Sobre este aspecto, Carvalho (2010), analisando hábitos de estudo e sua influência no rendimento escolar, coloca que a criação de um horário de estudo pode ajudar o aluno a compreender que 
existe uma necessidade de um estudo diário. Para a autora parece existir uma relação entre o número de horas de estudo e os resultados escolares: os alunos que estudam mais horas por dia têm tendência a terem melhores resultados escolares.

Na sexta questão os alunos deveriam expressar se consideram que o AVA ajudou na sua organização pessoal em relação aos conteúdos de estudo. A maioria, $96 \%$ dos alunos respondeu afirmativamente, ou seja, que o AVA estava contribuindo na sua organização pessoal em relação aos estudos, enquanto que, apenas $4 \%$ responderam que não estava. Fato que, mais uma vez, se demonstrou positivo, pois o AVA também deveria proporcionar maior autonomia aos alunos. Cabe destacar que, as tendências atuais na área de educação apontam para a utilização de metodologias ativas de ensino-aprendizagem, visando tornar o aluno o protagonista do seu próprio processo de formação, por isso a importância da organização pessoal em relação aos estudos.

Da mesma forma, na sétima questão os mesmos $96 \%$ recomendariam a utilização de AVA em outras disciplinas. Na oitava questão, referente à avaliação geral do AVA, $71 \%$ dos alunos avaliou-o como excelente, outros $25 \%$ avaliaram como bom e apenas $4 \%$ como médio.

Na nona questão, deveriam responder se acessaram as leituras complementares indicadas pela professora-pesquisadora: $59 \%$ dos alunos acessaram as leituras, porém $41 \%$ não acessaram, revelando um percentual bastante alto de não acesso.

Considerando que os alunos estão amplamente ligados nas redes sociais, na décima questão, sobre o acompanhamento das postagens no grupo criado no Facebook, a maioria, 83\% responderam que acompanhavam as postagens e apenas $17 \%$ não acompanhavam.

Os dados apresentados a seguir são referentes a questões abertas e para apresentá-los utilizou-se a técnica de análise de conteúdo proposta por Bardin (2011).

Na décima primeira questão os alunos deveriam responder qual a relação entre os materiais disponíveis no AVA e as aulas presenciais. Nesta questão houve um grande número de abstenções, ou seja, alunos que não responderam, totalizando $25 \%$. Ainda assim, $17 \%$ apontaram que o AVA tem "tudo a ver" com a aula, pois contém os conteúdos e atividades, outros $17 \%$ indicaram que o AVA ajuda a acompanhar a matéria da aula e outros $17 \%$ ressaltaram a possibilidade de acessar o AVA quando faltam a aula. Esta possibilidade de acessar os materiais quando não podem comparecer a aula não havia sido planejada no início da pesquisa, a ação partiu dos próprios alunos.

Na décima segunda questão os alunos deveriam apontar qual atividade desenvolvida no AVA mais gostaram de participar. A atividade de maior preferência foi de assinalar a resposta correta, com $30 \%$ dos alunos, outros $25 \%$ indicaram as questões de verdadeiro ou falso e $12 \%$ indicaram que gostaram de todas as questões.

194 DOI: Em andamento. 
Ainda na décima segunda questão os alunos deveriam indicar o porquê da preferência pela atividade. Os alunos que apontaram como preferência as atividades em que deveriam assinalar a resposta correta indicaram a semelhança destas questões com as das avaliações, a rapidez de fazer e de obter resposta (se acertou ou errou) e maior facilidade. Já os alunos que apontaram como preferências as atividades de verdadeiro ou indicaram a objetividade destas atividades.

Completando esta informação, os alunos foram questionados sobre a atividade desenvolvida no AVA que menos gostaram de participar (décima terceira questão). Assim sendo, a maioria, $42 \%$ dos alunos indicaram que não houve atividade que não gostou de participar. Este número possivelmente se relacione com os $30 \%$ que não responderam, pois neste caso, não responder poderia significar que não houve atividade que não gostou.

$\mathrm{Na}$ décima quarta questão os alunos deveriam responder se acreditavam que o AVA estava contribuindo para seu estudo e aprendizagem e justificar a sua resposta. Neste sentido, $83 \%$ dos alunos responderam que sim, o AVA estava contribuindo para seu estudo e aprendizagem. Como justificativa, 50\% deles apontaram o fato de o AVA ajudar a estudar ou ajudar a estudar especificamente para as avaliações, 17\% apontaram que através do AVA praticam o que aprenderam em aula ou que o AVA é complementar à aula, e outros $17 \%$ que o AVA ajudou a aprender mais ou aumentou o tempo de estudos em Ciências. Cabe destacar que $12 \%$ deles indicaram que entendem melhor as atividades no site que na aula e acham importante utilizar a tecnologia na aula. Esta constatação dos alunos se aproxima do pensamento de Moran (2009) que diz que as tecnologias estão mudando nossa forma de nos relacionarmos com o mundo, nossa forma de pensar, de ensinar e de aprender.

$\mathrm{Na}$ décima quinta questão os alunos deveriam responder se encontraram alguma dificuldade ao acessar os materiais no AVA. Sendo assim, $71 \%$ dos alunos responderam que não tiveram dificuldades, enquanto que $17 \%$ responderam que tiveram dificuldades e outros $12 \%$ não responderam a esta questão.

Os alunos que tiveram dificuldades em acessar, apresentaram esta dificuldade de acesso ao AVA em si, e não aos materiais. Deste modo, estes $4 \%$ que tiveram dificuldades em acessar apontaram como causa principal a incompatibilidade do navegador de internet utilizado (75\%) e outros $25 \%$ apontaram a baixa qualidade da internet 3 G. Os alunos que tiveram dificuldades em função do navegador utilizado foram orientados a baixar o navegador FireFox, cuja licença para utilização é gratuita.

$\mathrm{Na}$ décima sexta questão os alunos deveriam descrever como ocorre a sua aprendizagem no AVA. Dos respondentes, $46 \%$ indicaram que a aprendizagem ocorre através de atividades diferenciadas, porém $38 \%$ não responderam a esta questão. Outros $33 \%$ responderam que a aprendizagem no AVA ocorre com mais rapidez ou facilidade e $35 \%$ apontaram o uso de textos e apresentações em Prezi. Neste sentido, Macedo (2005) lembra que diante de um AVA vemos um 
cenário de mudanças nas relações interindividuais, na autonomia, na auto-organização dos sujeitos, além de um novo espaço e tempo de trabalho.

A décima sétima questão, referente aos facilitadores e o que dificulta a aprendizagem no AVA, 33\% dos alunos responderam que "tudo" no AVA facilita a aprendizagem, outros 33\% responderam que as atividades facilitam a aprendizagem Já em relação ao que dificulta a aprendizagem, $80 \%$ dos alunos não responderam, levando a concluir que nada em específico no AVA dificultou a aprendizagem, enquanto que $20 \%$ apontaram o uso da internet $3 G$.

Na décima oitava questão, os alunos deveriam descrever o AVA. Esta questão tinha como objetivo fazer com que os alunos revelassem, mesmo que de forma não intencional, o que mais havia Ihe chamado atenção no AVA. Infelizmente, $42 \%$ dos alunos abstiveram-se de responder. Outros 33\% dos alunos não efetuou exatamente uma descrição, apenas qualificou o AVA como um site útil para a turma ou para a aprendizagem da turma, $17 \%$ lembraram-se dos textos ou dos conteúdos presentes no AVA.

A penúltima questão, décima nona, questionava sobre o acesso ao Plano de estudos, e pedia para indicar se ele foi útil de alguma forma. O Plano de estudos era apresentado como uma aba no AVA que incluía os conteúdos, os objetivos da cada conteúdo, a bibliografia fundamental e complementar dentre outras informações. O principal objetivo ao disponibilizar o Plano de estudos era que os alunos pudessem ter uma visão geral, e, portanto não fragmentada dos conhecimentos que seriam abordados no ano, além disso, ao evidenciar aos alunos os objetivos de cada conteúdo, fica claro o que se espera em cada um deles. Como resposta, $63 \%$ dos alunos indicaram que acessaram o Plano de estudos, $25 \%$ não acessaram e $12 \%$ não responderam. Dentre os $63 \%$ que haviam acessado, $73 \%$ deles indicaram que sim, foi útil para as atividades, na compreensão dos conteúdos e para ajudar na organização pessoal.

A última questão (vigésima questão) pedia aos alunos para deixarem sugestões ou outros comentários. A única sugestão expressa em relação ao AVA em si, foi aumentar o número de atividades por conteúdo. Além desta, outra sugestão foi para expandir a ideia de utilizar o AVA para outras séries/anos e disciplinas. Esta sugestão evidencia o caráter qualificador para o ensino e da aprendizagem do AVA, reconhecido inclusive pelos alunos. E nos comentários, a avaliação do AVA como "muito bom" e que gostou muito de participar desta iniciativa.

Com o passar do tempo de utilização o AVA tornou-se uma ferramenta a mais para o estudo, aprendizagem e para a preparação para as avaliações. Isso ficou evidente quando os alunos indicaram que acessavam o AVA antes das avaliações. Moran (2009) lembra que as tecnologias não trarão soluções rápidas para o ensino, mas que, sem dúvida elas permitem ampliar o conceito de aula, de espaço e de tempo e de comunicação, estabelecendo novas pontes entre o presencial e o virtual.

196 DOI: Em andamento. 
A maioria dos alunos percebeu que o AVA aumentou o seu tempo de estudos, possivelmente estabelecendo o hábito de estudar antes das avaliações, o que muitas vezes não ocorria. É muito comum os alunos relatarem que não estudaram para uma avaliação, ou mesmo que não estudam em casa. $O$ que se percebe é que eles têm dificuldade em estudar, em dominar técnicas de estudo e em reconhecer sua própria forma de aprender. Sobre este aspecto Macedo (2005) em um estudo com abordagem semelhante a este, lembra que o clássico ambiente educacional tem seu espaço e tempo limitados e determinados, já nos ambientes virtuais as possibilidades se ampliam, ocorrendo uma adaptação do tempo e do espaço às necessidades dos alunos.

Neste sentido, também se pode afirmar que o AVA contribuiu positivamente, uma vez que os alunos relataram que a utilização do ambiente auxiliou na sua organização pessoal em relação aos estudos. Ao disponibilizar os materiais das aulas e atividades complementares, além de outros recursos que poderiam ser acessados em qualquer lugar e hora, o AVA estimulava os alunos a percorrerem caminhos próprios de aprendizagem. Nesta perspectiva, Macedo (2005) destaca a importância da ação do sujeito, pois é através dela que se constroem as estruturas para o conhecimento.

Um dos principais aspectos a serem considerados neste trabalho é a clareza das percepções dos alunos em relação às contribuições do AVA para sua aprendizagem. Apesar do foco desta pesquisa não estar nos resultados quantitativos da avaliação, cabe destacar que os alunos que acessaram o AVA obtiveram um resultado $7 \%$ superior na avaliação trimestral quando comparados aos que não acessaram.

\section{Considerações finais}

A partir dos resultados obtidos conclui-se que os alunos participantes da pesquisa não encontraram dificuldades em acessar o AVA proposto. Além disso, os alunos revelaram que com a utilização do AVA houve um aumento no tempo de estudos para a disciplina Ciências, da mesma forma que o AVA contribuiu para sua aprendizagem de diferentes formas. A investigação revelou que os alunos fizeram uma avaliação positiva do ambiente e que reconhecem que o AVA auxiliouos na organização pessoal para o estudo.

Apesar de o resultado ter sido positivo, algumas questões ainda permanecem para outras pesquisas como, por exemplo, o reflexo da utilização de um AVA no desempenho dos alunos, a formação docente para o uso das TIC e, principalmente, a melhoria das condições das escolas públicas para utilizar as tecnologias em todas as aulas e em todas as etapas dos processos de ensino e aprendizagem.

Durante toda a pesquisa, desde o projeto até a execução, houve a preocupação de desenvolver um estudo que considerasse as condições reais de ensino de muitas escolas públicas 
na atualidade. Isso se verifica na escolha das ferramentas que foram incorporadas ao AVA, todas de uso gratuito e em português ou no máximo, em espanhol (no caso do EducaPlay) e da própria plataforma para desenvolver o AVA. Além de serem gratuitas, estas ferramentas deveriam ser simples e práticas, não requerendo conhecimentos avançados em informática para operá-las. Assim sendo, acredita-se que esta pesquisa pode ser um contributo a outros professores que desejam iniciar a incorporação das TIC em suas aulas.

\section{Referências}

BARDIN, Laurence. Análise de conteúdo. São Paulo: Edições 70, 2011.

CARVALHO, Patrícia da Silva. Hábitos de estudo e sua influência no rendimento escolar. 2012. 164p. Dissertação de mestrado. (Mestrado em Psicologia Clínica e da Saúde), Faculdade de Ciências Humanas e Sociais, Universidade Fernando Pessoa, Porto, 2012.

FERNANDES, Luís. Redes Sociais Online e Educação: Contributo do Facebook no Contexto das Comunidades Virtuais de Aprendentes. Lisboa, 2011. Disponível em: <http://seer.ufrgs.br/renote/article/viewFile/36434/23529> Acesso em: 7 jul. 2014.

GODOY, Arilda Schmidt. Pesquisa qualitativa: tipos fundamentais. Revista de administração de empresas, São Paulo, v. 35, n. 3, p. 20-29, maio/junho. 1995.

JULIANI, Douglas Pauleski; JULIANI, Jordan Pauleski; SOUZA, J. A.; BETTIO, Raphael Wincler. Utilização das redes sociais na educação: guia para o uso do Facebook em uma instituição de ensino superior. Revista Novas Tecnologias na Educação, Porto Alegre, v. 10, n. 3, p.01-11, dezembro. 2012.

LÉVY, Pierre. O que é o virtual? São Paulo: Ed 34, 2001.

MACEDO, Alexandra Lorandi. Aprendizagem em ambientes virtuais: o olhar do aluno sobre o próprio aprender. 2005. 174p. Dissertação de Mestrado. (Mestrado em Educação), Faculdade de Educação, Universidade do Rio Grande do Sul, Porto Alegre, 2005.

MAN, Cris. \& STEWART, Fiona. Internet communication and qualitativa research: a handbook for reaserching on-line. London: Sage, 2002.

MARTINHO, Tânia; POMBO, Lúcia. Potencialidades das TIC no ensino das Ciências Naturais-um estudo de caso. REEC: Revista electrónica de enseñanza de las ciencias, Vigo, v. 8, n. 2, p.527538, 2009.

MENEZES, Vera. O computador: um atrator estranho na educação linguística na América do Sul. Revista Tecnologias na Educação, v. 1, n. 1, p. 1-22, 2009.

MORAN, José Manuel. Novas tecnologias e mediação pedagógica. Campinas: Papirus Editora, 2009.

198 DOI: Em andamento.

R. Bras. de Ensino de C\&T 
ONOFRE, Dari. Escolanet: O Uso de Ambiente Virtual de Aprendizagem (AVA) como Ferramenta de Apoio e Estímulo à Aprendizagem de Física no Ensino Médio. 2010. 108p. Dissertação de Mestrado. (Mestrado Profissional em Ensino de Ciências Exatas), Universidade Federal de São Carlos, São Carlos, 2010.

PAULETTI, Fabiana; CATELLI, Francisco. Tecnologias Digitais: possibilidades renovadas de representação da química abstrata. Acta Scientiae, Canoas, v. 15, n. 2, p. 383-396, 2013.

PALFREY, John Gorham; GASSER, Urs. Nascidos na era digital: entendendo a primeira geração de nativos digitais. Artmed, 2011.

PIVA JR, Dilermando. Sala de Aula Digital: uma introdução à cultura digital para educares. São Paulo: Saraiva, 2013.

TAVARES, Kátia. Novas tecnologias e novas linguagens - formando comunidades de aprendizagem on-line para o ensino de línguas. Caderno de Letras, Rio de Janeiro, p. 129-136, 2003.

VALENTINI, Carla Beatris; SOARES, Eliana Maria do Sacramento. Aprendizagem em ambientes virtuais: compartilhando idéias e construindo cenários. Caxias do Sul, 2010. Disponível em: < http://www.ucs.br/etc/revistas/index.php/aprendizagem-ambientes-

virtuais/article/viewFile/393/323 >. Acesso em: 19 maio 2014.

VETROMILLE-CASTRO, Rafael. A usabilidade e a elaboração de materiais para o ensino de inglês mediado por computador. Revista Brasileira de Linguística Aplicada, v. 3, n. 2, p. 9-23, 2003.

YIN, Robert. Estudo de caso: planejamento e métodos. Porto Alegre: Bookman, 2001.

Roberta Dall Agnese da Costa

Mestre em Ensino de Ciências e Matemática

Universidade Luterana do Brasil - ULBRA

Caroline Medeiros Martins de Almeida

Mestre em Ensino de Ciências e Matemática

Universidade Luterana do Brasil - ULBRA

Paulo Tadeu Campos Lopes

Doutor em Fitotecnia

Universidade Luterana do Brasil - ULBRA

DOI: Em andamento. 